Case Report

\title{
Towards Zero Emissions Noosa
}

\author{
Carina Anderson ${ }^{1,2, *}$, Robert Passey ${ }^{3}$, Jeremy De Valck ${ }^{4}(\mathbb{D}$ and Rakibuzzaman Shah 5 \\ 1 School of Nursing, Midwifery and Social Sciences, CQUniversity, Noosa, QLD 4566, Australia \\ Zero Emissions Noosa Inc., Noosa, QLD 4567, Australia \\ 3 School of Photovoltaic and Renewable Energy Engineering, University of New South Wales (UNSW), \\ New South Wales, SYD 2052, Australia \\ 4 School of Business and Law, CQUniversity, Brisbane, QLD 4000, Australia \\ 5 School of Engineering and Technology, CQUniversity, Perth, WA 6000, Australia \\ * Correspondence: c.anderson@cqu.edu.au
}

Received: 26 July 2019; Accepted: 20 August 2019; Published: 28 August 2019

check for updates

\begin{abstract}
This paper reports on a case study of the community group Zero Emissions Noosa, whose goal is for 100\% renewable electricity in the Noosa Shire (Queensland, Australia) by 2026. Described within this paper are the processes used by Zero Emissions Noosa to set up their zero emissions plan, involving community engagement and the use of an external consultant. The external consultant was employed to produce a detailed report outlining how to successfully achieve zero emissions from electricity in the Noosa Shire by 2026. This paper explains how and why the community engagement process used to produce the report was just as important as the outcomes of the report itself. Modeling was undertaken, and both detailed and contextual information was provided. Inclusion of the community in developing the scenario parameters for the modeling had a number of benefits including establishing the context within which their actions would occur and focusing their efforts on options that were technically feasible, financially viable and within their capabilities to implement. This provided a focal point for the community in calling meetings and contacting stakeholders. Rather than prescribing a particular course of action, it also resulted in a toolbox of options, a range of possible solutions that is flexible enough to fit into whatever actions are preferred by the community. The approach and outcomes discussed in this paper should, therefore, be useful to other communities with similar carbon emission reduction goals.
\end{abstract}

Keywords: Noosa; community; zero emissions; renewable energy; modeling; toolbox of options

\section{Introduction}

The Paris Agreement identifies the need to keep global warming below $2{ }^{\circ} \mathrm{C}$, and preferably no more than $1.5^{\circ} \mathrm{C}$, as urgent [1]. Governments have been slow to act to implement the policies and programs required to achieve the Paris Agreement goals [2]. For this reason, on-the-ground community initiatives are needed to decrease carbon emissions [3,4]. Nevertheless, engaging communities with such an abstract goal can be difficult [5].

In Australia, various initiatives are being launched to help meet the Paris Agreement through encouraging the transition to renewable energy sources. The Australian Government's Large-scale Renewable Energy Target (LRET) scheme is legislated for 33,000 GWh of renewable electricity generation by 2020, maintained until 2030 [6]. It is expected to result in about $23.5 \%$ of Australia's electricity coming from renewable sources [6]. Several states within Australia have also set ambitious targets for emission reductions and increases in renewables-although these are not legislated and so are only aspirational, and for all but the ACT target, are not additional to the LRET. For example, the Victorian State Government [7] has set renewable energy targets of $25 \%$ by 2020 and $40 \%$ by 2025 , and the Australian Capital Territory (ACT) has set a 100\% renewable energy target by 2020 [8]. The renewable 
energy target for the State of Queensland (Qld) is set at 50\% by 2030 [9]. To achieve this target, it is estimated that an additional $5500 \mathrm{MWp}$ of renewables is needed in Queensland by 2020 [9]. The targets set for various Australian jurisdictions are summarised in Table 1.

Table 1. Proposed actions in various Australian jurisdictions (Adapted [9], p.42).

\begin{tabular}{cc}
\hline Jurisdiction & Target \\
\hline Australian Capital Territory (ACT) & $100 \%$ renewable energy by 2020 \\
South Australia (SA) & $50 \%$ renewable energy by 2025 \\
Victoria (Vic) & $25 \%$ renewable energy by 2020 and $40 \%$ by 2025 \\
Queensland (Qld) & $50 \%$ renewable energy by 2030 \\
\hline
\end{tabular}

Australia's population is largely urban (86\%) [10], and mostly concentrated in five areas: Sydney (NSW), Melbourne (Vic), Brisbane (Qld), Perth (WA) and Adelaide (SA). Economic activity and the pollution that comes with it are, therefore, for a large part associated with these cities, and so they have been developing strategies to reduce greenhouse gas emissions. In 2003, the City of Melbourne (the second largest city in Australia) issued a plan to achieve zero emissions by 2020 [11]. Sydney (the largest city in Australia) followed Melbourne's example and launched "Sustainable Sydney 2030", a plan to make Sydney a green, global and connected city [12]. Brisbane City Council became $100 \%$ carbon neutral in 2017 [13]. In March 2016, Perth City Council adopted the City of Perth's Environment Strategy, a 15-year plan working towards multiple sustainability goals [14]. Adelaide City Council—the last of the five largest Australian cities-is aiming to have zero emissions from council operations, including council operated transport, by 2020 [15].

Apart from the main urban areas, carbon emission reduction initiatives are gaining ground in smaller communities across Australia. Back in 1999, Frankston City Council [16] (Vic) adopted a "Greenhouse Strategy" to reduce greenhouse gas emissions, leading later to a "Carbon Neutral Action Plan" in 2012 [16]. Frankston City Council expects to become carbon neutral by 2025. Also in Victoria, Moreland City Council [17] launched a climate change action plan called "Zero Carbon Evolution Strategy 2014-2020" and aims to reduce carbon emissions in the Moreland community by $22 \%$ by 2020 . On a more regional scale, Byron Bay (NSW) was the first regional Australian shire to commit to zero emissions and aims to do so by 2025 [18]. A similar plan has been launched in Noosa Shire (Qld). This paper reports on the process used by Zero Emissions Noosa to start them on the path to reducing Noosa Shire's emissions to zero by 2026.

Noosa Shire is a small community, with a population of just over 50,000, located in South East Queensland, Australia, about $130 \mathrm{~km}$ north of Brisbane on the Sunshine Coast. Noosa Shire has a history of a number of community-led environmental conservation initiatives, operated through various organizations. One of these organizations is Noosa Parks Association, a community-based conservation organization run and led by local volunteers [19]. Over the years, Noosa Parks Association has rallied to protect the natural beauty of the Noosa area and in doing so has battled with local and state governments to have land in the Noosa area converted into national parks [20]. The Noosa National Park and the Cooloola National Park only exist today because of the Noosa Parks Association's efforts to convince the state government to protect the pristine environment in these areas [20]. The last council election, held in 2016, saw residents of the Noosa Shire elect an environmentally conscious Council that reflects the same values as its community members [21].

Zero Emissions Noosa was formed in 2016 and has a community objective to achieve zero net emissions by 2026. Zero Emissions Noosa was based on a similar group, Zero Emissions Byron, that was formed in 2015 in Byron Bay, New South Wales, and has a community objective to achieve zero net emissions in Byron Shire by 2025 [18]. Six months after the first Zero Emissions Noosa meeting, in support of the ambitious zero emissions goal, fourteen different community, and business organizations in Noosa Shire (Country Noosa, CQUniversity, Noosa Biosphere, CCIQ, Noosa Community Biosphere Association (NCBA), Noosa Council, Noosa and District Landcare, Noosa Integrated Catchment Association Inc, Noosa Parks Association, Noosa Resident and Rate Payers Association Inc., D2 
co-working Noosa Junction, Sunshine Coast environment Council, Tourism Noosa, University of the Sunshine Coast.) signed a memorandum of understanding (MoU) with Zero Emissions Noosa. Supporting organizations signed the MoU at a public event where they formally announced their commitment to support Zero Emissions Noosa's goal.

In 2015 Noosa Shire produced around 345,000 tonnes of greenhouse gas (GHG) emissions [22]. Most of Noosa Shire's GHG emissions come from three main sources: Electricity use, transport and waste [22]. Supporting the local community's zero emissions goal, Noosa Council has set its own target of "zero net emissions in Council's operations and services" by the year 2026 [23]. Waste is one of Noosa Council's largest sources of GHG emissions and is one of council's core businesses [24], so Zero Emissions Noosa decided to focus on electricity use and transport, leaving the reduction of emissions from waste to Noosa Shire Council. Zero Emissions Noosa formed two working subgroups: The electricity subgroup and the transport subgroup [22]. Zero Emissions Noosa, and its electricity and transport subgroups, are examples of the challenges and opportunities of a local community group striving to mitigate the effects of climate change. This paper focuses on the process used by the electricity subgroup to develop a $100 \%$ renewable electricity plan.

\section{Methods}

Zero Emissions Noosa decided a plan was needed to achieve its $100 \%$ renewable electricity goal, and so they sought assistance from an external consultant in the development of a conceptual framework and the formulation of appropriate strategies. Members of Zero Emissions Noosa were aware of reports produced for Byron Shire and East Gippsland Shire to help them increase their share of renewable electricity, that had been undertaken by ITP Renewables, a renewable energy consultancy (hereafter referred to as ITP). Zero Emissions Noosa, therefore, applied for funding to the Noosa Biosphere Reserve Foundation (which is itself funded by Noosa Council using funds from its Environmental Levy), to duplicate that work in Noosa [25]. The funding from the grant was used to employ ITP as an external consultant to develop a report for Zero Emissions Noosa that outlined a strategy for achieving the $100 \%$ renewable electricity goal.

The process of producing the report [26] was just as important as the outcomes of the report itself. This process included a series of consultations with the broader community as well as with Noosa Shire Council. This not only provided valuable feedback regarding the interest of the Noosa community and council in different strategies to increase the uptake of renewable energy, but also provided feedback on modeling assumptions, and importantly, made the activities of Zero Emissions Noosa very visible to the community. The report, entitled Achieving $100 \%$ Renewable Electricity in Noosa, is an electricity transition plan that consists of four components that have different functions and impacts on community engagement, motivation, and guidance. These are: (i) Modeling, (ii) high-level issues, (iii) possible business models and (iv) specific recommendations (referred to as a toolbox of options). A flowchart illustrating the processes used by ITP to develop an energy transition plan for Zero Emissions Noosa is found in Figure 1.

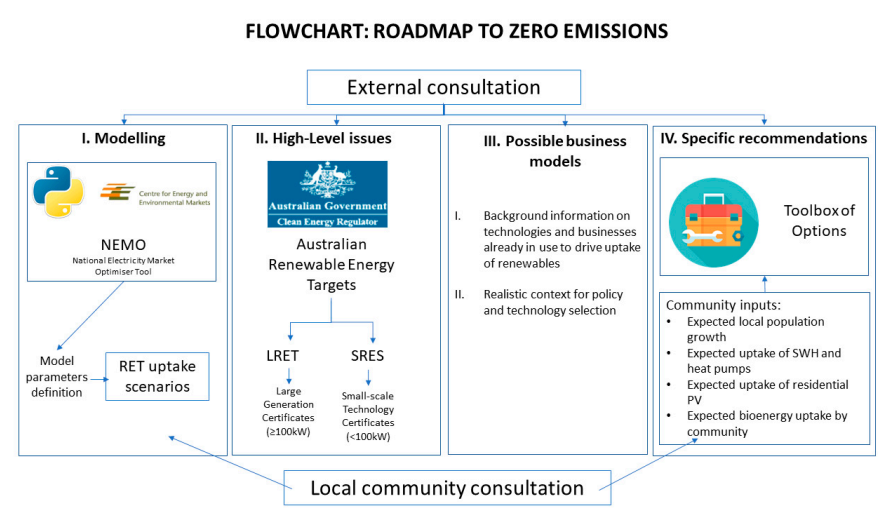

Figure 1. Flowchart: Roadmap to zero emissions. 


\subsection{Modeling}

The modeling component produced by ITP was undertaken using the open source software NEMO (National Electricity Model Optimiser) that was used to model the hour-by-hour dispatch of a range of electricity generation technologies according to the scenarios developed by the Noosa community. NEMO was developed at the University of New South Wales, Australia, specifically so that smaller groups with restricted access to funding could undertake modeling themselves, and not rely on outcomes presented to them by governments and large consulting firms.

Modeling was a critical component of the community engagement process. The first reason it was critical is that the community was involved in setting the parameters for the model, which provided a focal point for them to think about what is reasonable and feasible in terms of the level of uptake of different renewable energy technologies. It helped them to think about all of the different influences that affect the level of electricity use (for example increased uptake due to population increase, increased affluence and the uptake of electric vehicles, and decreased electricity use due to specific programs, increased uptake of specific technologies such as solar water heaters and the natural progression of technologies to be more energy efficient) and well as the various renewable energy technologies that can generate electricity.

The second reason that modeling was critical was that it provided a realistic forecast of what may occur if the various recommendations were implemented. For example the Noosa community learned about the relative impacts of given percentages of the households installing a $5 \mathrm{kWp}$ photovoltaic (PV) system versus the same number of households installing a solar water heater (SWH) - both in terms of the relative reduction in electricity drawn through the zone substations (ZSs) and in terms of the temporal impacts of these technologies (i.e., PV during the day and SWHs generally reducing overnight electricity use). Another high-level impact that was well illustrated through modeling was the effect of a single technology type making a significant contribution to the target. High penetration of PV resulted in a large amount of excess electricity during the day, which would be exported back through the ZSs most likely resulting in significant voltage rise, and a concomitant need to import electricity during the night. This illustrated the benefits of both load shifting (from night to day) and the use of batteries to soak up excess solar generation.

The third reason is that modeling gave the report credibility in the eyes of the community, businesses and government. Of course, the outputs of any model are only as good as the assumptions and input parameters, but in this case, it was used only to provide high-level guidance on parameter choices rather than accurate forecasts. Feedback from the various workshops with the community, business groups and government made it clear that modeling provided credibility to the report because it illustrated the impacts of different policy decisions.

The final reason that modeling was a critical component is that it generated visual aids that could be used during community consultation events. Images that help create a more interesting and informative narrative are very important when the community will be relied upon to help develop and implement any action plans [27].

\subsection{High-Level Issues}

This section of the report was important because increasing the uptake of renewables is not simply a matter of identifying the technologies to be used and then selecting appropriate business models to drive uptake. It is important that the community understands how its choices fit into the overarching regulatory environment. An overview of the Australian regulatory environment is presented in Appendix A, but in summary, it explains why systems greater than $100 \mathrm{kWp}$ will not be additional to legislated targets, why the legislated schemes in Australia do not reduce the amount of renewable electricity required for Noosa to reach its $100 \%$ goal, and the factors that need to be taken into consideration for renewable electricity to count towards Noosa's targets. 


\subsection{Possible Business Models}

This section of the report had two main functions. The first function was to provide valuable background information on the various technologies and business models already being used in Australia, especially by community groups, to drive the uptake of renewable energy technologies. This helped to focus the community on options that were likely to be realistic because they were technically feasible, financially viable and within their capabilities to implement. It also meant that the subsequent section on specific recommendations could be much more focussed, making it more accessible for members of the community wanting to just get on and do something' without reading through pages of explanations. The second function was to provide credibility to the report. It showed that the recommendations were well-founded in the current policy and technology environment and provided the context for their selection.

\subsection{Toolbox of Options}

The specific recommendations in the Noosa report form a toolbox of options (described in Section 3) that were the culmination of consultations with community groups, businesses and local governments in three different local government areas (LGAs): Byron Shire, East Gippsland Shire, and Noosa Shire. As such, they represent the benefits of an extended consultation process that has taken place over three separate areas and a period of two years. Whereas the Byron consultation process was limited to selected individuals, the East Gippsland process included a series of 'one-on-one' meetings with state government departments, the local council, businesses, individuals and two community meetings. The Noosa process did not include any 'one-on-one' meetings but revolved more around three larger meetings with community/business combined, as well as with Noosa Council. Three community consultation meetings were held in Noosa to inform the public of the outcomes of the ITP report. These involved ITP firstly presenting a set of preliminary modeling outcomes (using parameters recommended by ITP based on previous work in similar communities), then describing different options for the residential, commercial and community sectors to drive the uptake of renewables (again based on previous work by ITP). Although the community was asked for new options to drive the uptake of renewables, no new options were identified. During these meetings, the community was invited to provide verbal and written feedback on the report. Their written feedback was received via the Zero Emissions Noosa website. This feedback was collated by four members of Zero Emissions Noosa and then sent on to ITP. The resultant recommendations included a good mix of options for all sectors of the community.

\section{Results}

In this section, the level of electricity use is firstly described in Noosa Shire, followed by the amount of small-scale renewable energy generation. The modeling scenarios used, as well as the scenario outcomes and the toolbox of options that can be used to help drive uptake of renewable energy technologies, are then illustrated.

\subsection{Electricity Use and PV Generation in Noosa Shire}

The electricity use in Noosa LGA in 2016/17 was calculated from half-hourly data provided by Energex, the relevant network operator. It was 312,463 MWh, consisting of 173,091 MWh (55.4\%) from the residential sector, $136,722 \mathrm{MWh}(43.8 \%)$ from business, and $2650(0.8 \%)$ from street lighting.

Solar PV is by far the most prevalent form of distributed generation in Noosa LGA, with no wind, bioenergy or hydro systems registered with the Australian Clean Energy Regulator. As at May 2018, there was 28,909 kWp PV installed in Noosa LGA [28]. This consisted of 8031 systems $(26,064 \mathrm{kWp})$ that were less than $10 \mathrm{~kW}$ in size (assumed to be residential systems), and 145 (2845 kWp) in the $10 \mathrm{kWp}$ to $100 \mathrm{kWp}$ size range (assumed to be commercial systems). Although there are about 26,750 dwellings in Noosa LGA, only about 23,250 of these are considered to have suitable roof space for PV 
and solar water heaters (SWHs) (Derived from the ABS [29] and APVI Solar Map [28]). Thus, with 8031 PV systems in the sub $10 \mathrm{kWp}$ size range, about $35 \%$ of suitable dwellings had PV, and the average residential system size was about $3.25 \mathrm{kWp}$. With an estimated 3050 businesses in Noosa LGA, about $4.7 \%$ of them had solar PV, with an average size of about $20 \mathrm{kWp}$.

The electricity generation from distributed PV in Noosa shire was calculated using the average hourly generation of typical rooftop PV systems within Noosa LGA (PV data was sourced from publicly available PV performance database provided by PVOutput.org). The hourly generation over a year was then estimated by scaling the number and the size of PV systems in Noosa LGA (Derived from APVI Solar Map [28]). The same scaling method was used to estimate the hourly generation from future installations of behind-the-meter PV for each scenario (e.g., Base case and Stretch as discussed below). The estimated generation from PV systems was 41,300 MWh and so the real underlying use of electricity in Noosa was 353,964 MWh. The load as seen by the zone substations (Net load, orange) and what the load would have been if it had not been for the existing PV systems (Load, blue) as seen by the zone substations during the peak weeks in summer and winter are given in Figure 2. The highest peaks in summer occur due to the combination of higher visitor numbers and air conditioning load and are reduced by PV generation. During the winter evenings, small spikes are visible due to the activation of off-peak water heating.

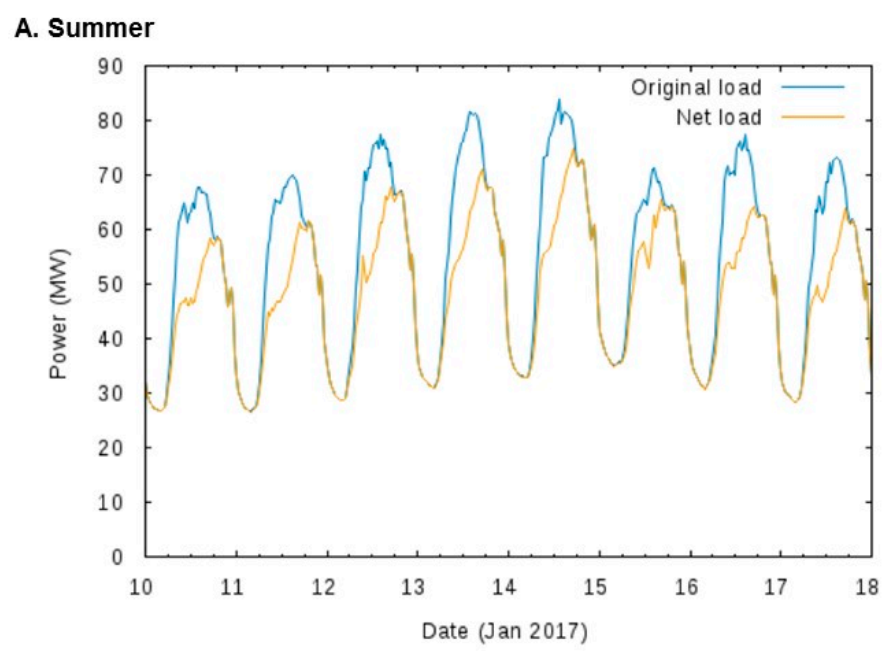

B. Winter

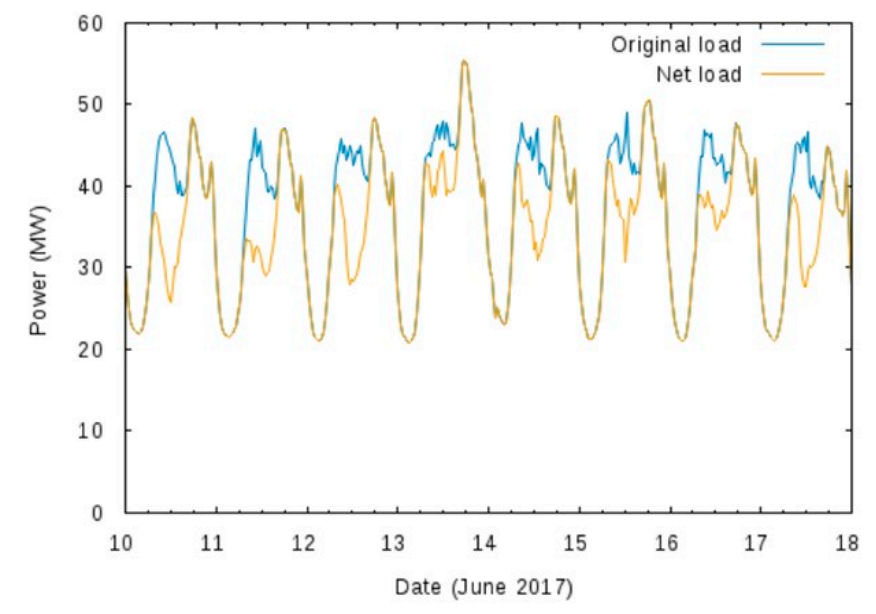

Figure 2. Peak weeks for Noosa LGA: (A) Summer, (B) winter [26].

\subsection{Community Determined Scenarios and Modeling Outcomes}

Two scenarios are considered in 2026 for Noosa Shire: A Base case and a Stretch case (Table 2). These scenarios are not predictions, instead they illustrate the impact of different levels of generation and 
consumption of electricity. They were based on previous ITP reports for Byron Shire and East Gippsland Shire, as well as on consultation with the Noosa community. Rather than presenting the modeling outcomes in detail, they are summarised here to illustrate the Noosa context and the information presented to the Noosa community. The two scenarios were community-determined. Firstly, via the community meetings, the public were invited to offer their feedback on scenario parameters/projections based on what they considered to be realistic for the Noosa Shire. Then, over the course of several meetings, Zero Emissions Noosa members deliberated over these parameters/projections and collaboratively decided on Base Case and Stretch Case scenarios.

Table 2. Community determined scenarios: Base case and Stretch case.

\begin{tabular}{cccc}
\hline & $\mathbf{2 0 1 6}$ & Base Case & Stretch Case \\
\hline Residential PV & $26.1 \mathrm{MWp}$ & $48.1 \mathrm{MWp}$ & $80.5 \mathrm{MWp}$ \\
Commercial PV & $2.7 \mathrm{MWp}$ & $30.7 \mathrm{MWp}$ & $43.1 \mathrm{MWp}$ \\
SWH/heat pumps & $17.1 \%$ & $26.4 \%$ & $50 \%$ \\
Bioenergy & & & $1 \mathrm{MWp}$ \\
Population growth & $8.44 \%$ & $8.44 \%$ \\
Electric vehicle uptake & $10 \%$ & $20 \%$ \\
Energy efficiency & $-5 \%$ & $17.1 \%$ \\
Total large-scale PV/wind needed & & $104 / 75 \mathrm{MWp}$ & $56 / 40 \mathrm{MWp}$ \\
\hline
\end{tabular}

Scenario 1 Base case: This scenario considers a modest uptake of renewable energy and energy efficiency options. Under this scenario, the household PV increases from 26.1 MWp to $48.1 \mathrm{MWp}$, while commercial PV increases from 2.7 MWp to 30.7 MWp. Solar water heaters (SWH)/heat pumps increase from being on $17.1 \%$ of houses to being on $26.4 \%$. The population increases by $8.44 \%, 10 \%$ of vehicles are assumed to be electric vehicles (EVs) and there is only a $5 \%$ reduction in average per capita electricity use because of energy efficiency. As a result, $104 \mathrm{MWp}$ of large-scale ground-mounted PV or $75 \mathrm{MWp}$ of wind is required to achieve the $100 \%$ renewable target.

Scenario 2 Stretch case: This scenario presents a realistic but ambitious uptake of renewable and energy efficiency in the general community. The total penetration level of residential and commercial PV increases to $80.5 \mathrm{MWp}$ and $43.1 \mathrm{MWp}$ respectively, SWHs/heat pumps are installed by $50 \%$ of houses, however only $1 \mathrm{MWp}$ of bioenergy is installed. Population growth is the same $(8.44 \%)$ and energy efficiency reduces average per capita electricity use by $17 \%$. However, in keeping with the community's increased interest in behind-the-meter PV and energy efficiency, there is also increased interest in EVs (20\% of vehicles), which offsets the effects of increased energy efficiency. In this case, $56 \mathrm{MWp}$ of large-scale PV or $40 \mathrm{MWp}$ of wind is required.

The modeling process involved firstly projecting electricity use from 2016/17 allowing for population growth, uptake of SWHs, and the uptake of energy efficiency options in general. Different levels of uptake of distributed smaller-scale PV, bioenergy and GreenPower (GreenPower is a government-run program where customers can purchase renewable electricity that is certified to be additional to the LRET) purchase were then programmed into the model according to the above scenarios. This then allowed the amount of large-scale PV or wind generation to be calculated to meet the $100 \%$ renewable energy target over the year. It was assumed that electricity could be drawn from the National Electricity Market (NEM) when required (most likely overnight), then exported to the NEM when in excess (most likely during the day).

The combined impact of the above-mentioned options excluding large-scale PV and wind is given in Table 3. The total electricity use projected for 2026 ranges from a growth of $4.6 \%$ to a reduction of 8.7\% compared to 2016/2017. The combined effect of distributed PV, wind, bioenergy and GreenPower purchase results in significant amounts of either large-scale ground-mounted PV or large-scale wind power needed to meet demand over the year-see Table 4. For PV, $104 \mathrm{MWp}$ (Base case) and $56 \mathrm{MWp}$ (Stretch) are required, and for wind, $75 \mathrm{MWp}$ (Base case) and $40 \mathrm{MWp}$ (Stretch) are required. 
Table 3. Impacts on 2016/2017 electricity demand as seen by the zone substation.

\begin{tabular}{ccc}
\hline & Base Case & Stretch Case \\
\hline Population growth & $+8.44 \%$ & $+8.44 \%$ \\
SWHs/heat pumps & $-1.3 \%$ & $-5.2 \%$ \\
General energy efficiency & $-5 \%$ & $-17 \%$ \\
Sub total & $2.1 \%$ & $-13.8 \%$ \\
Electric Vehicles & $2.5 \%$ & $5.1 \%$ \\
Total Impact on Electricity Use & $4.6 \%$ & $-8.7 \%$ \\
Distributed PV & $-31 \%$ & $-48.5 \%$ \\
Bioenergy & $0 \%$ & $-2.5 \%$ \\
Total Impact of Distributed Generation & $-26.4 \%$ & $-59.7 \%$ \\
GreenPower & $-0.5 \%$ & $-1 \%$ \\
\hline TOTAL & $-\mathbf{2 7} \%$ & $-\mathbf{6 1 \%}$ \\
\hline
\end{tabular}

Table 4. The amounts of large-scale photovoltaic (PV) or large-scale wind required under each scenario and electricity generated in Noosa (2026).

\begin{tabular}{cccc}
\hline & Large-Scale PV & Large-Scale Wind & Electricity Generated \\
\hline Base case & $104 \mathrm{MWp}$ & $75 \mathrm{MWp}$ & $228 \mathrm{GWh}$ \\
Stretch & $56 \mathrm{MWp}$ & $40 \mathrm{MWp}$ & $123 \mathrm{GWh}$ \\
\hline
\end{tabular}

Table 5 summarises the percentage contribution to electricity generation for each of the renewable energy technologies in 2026. These values are different from those in Table 3, which are relative to the electricity use in 2016/17. In the Stretch case, distributed PV makes up more than half of the total renewable generation.

Table 5. Contribution to 2026 electricity generation.

\begin{tabular}{ccc}
\hline & Base Case & Stretch Case \\
\hline Distributed PV & $30 \%$ & $54 \%$ \\
Bioenergy & $0 \%$ & $3 \%$ \\
Large-scale PV or wind & $\mathbf{7 0} \%$ & $43 \%$ \\
\hline TOTAL & $\mathbf{1 0 0} \%$ & $\mathbf{1 0 0} \%$ \\
\hline
\end{tabular}

Figures 3 and 4 illustrate the electricity generation from the mix of renewable energy technologies in Noosa LGA for 2026. For each scenario, a summer peak week and a winter peak week are shown. Each of the colors represents a different technology (or category of technology such as residential or commercial PV). The slightly thicker black line shows the level of demand, and where generated electricity is exported, a paler version of the technology's color is used. The brown areas represent electricity imported from the Queensland grid. Note that large-scale wind has not been included in the charts because it would not be built in Noosa. As discussed in Section 3.1, this illustrates the likelihood of reverse power flow and voltage rise at high levels of PV uptake.

The impact of some households (25\% in the Base case scenario and $40 \%$ in the Stretch scenario) with PV also installing batteries with a $5 \mathrm{kWh}, 10 \mathrm{kWh}$ capacity ( $8 \mathrm{kWh}$ useable) was modelled. They were assumed to charge using excess solar electricity then to discharge from 6 p.m. on a daily basis. The battery generation is given in grey in Figures 3 and 4 and makes a more significant contribution in the Stretch scenario. The use of batteries in this way may reduce the amount of reverse power flow. Of course, load shifting through demand management, such as moving off-peak water heating to the middle of the day, would also be very effective. 

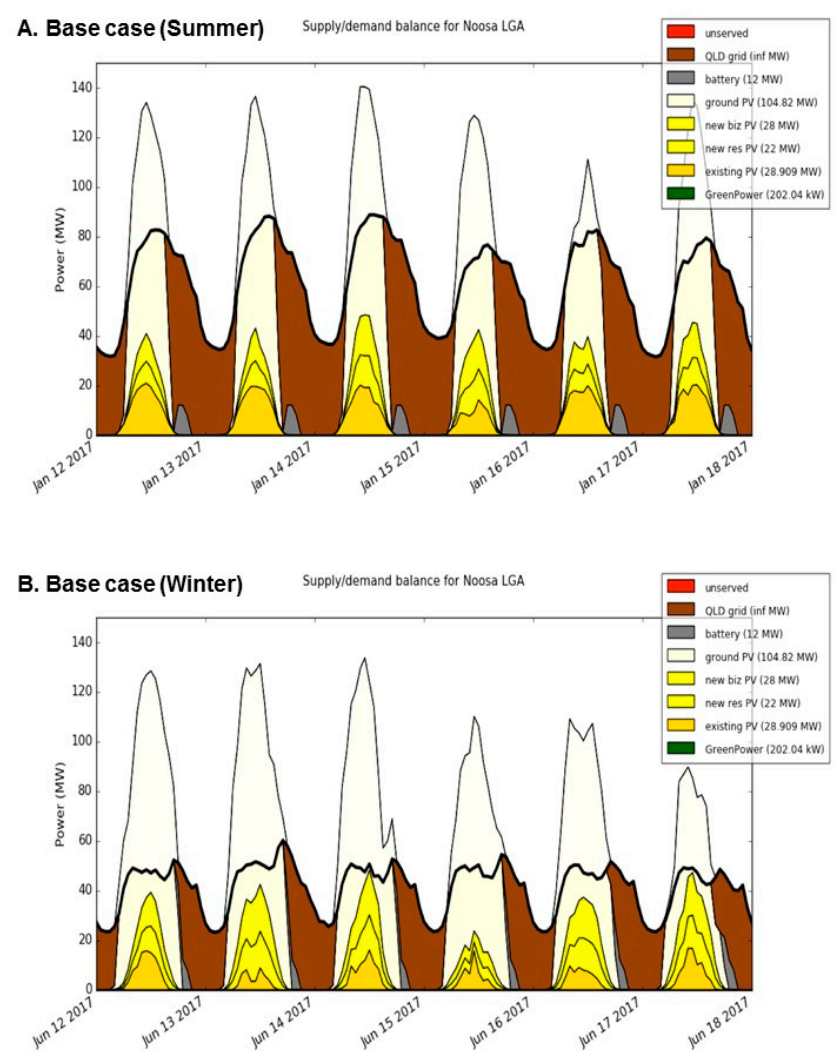

Figure 3. RE technology mix for Noosa-Base case ((A) summer, (B) winter) [26].
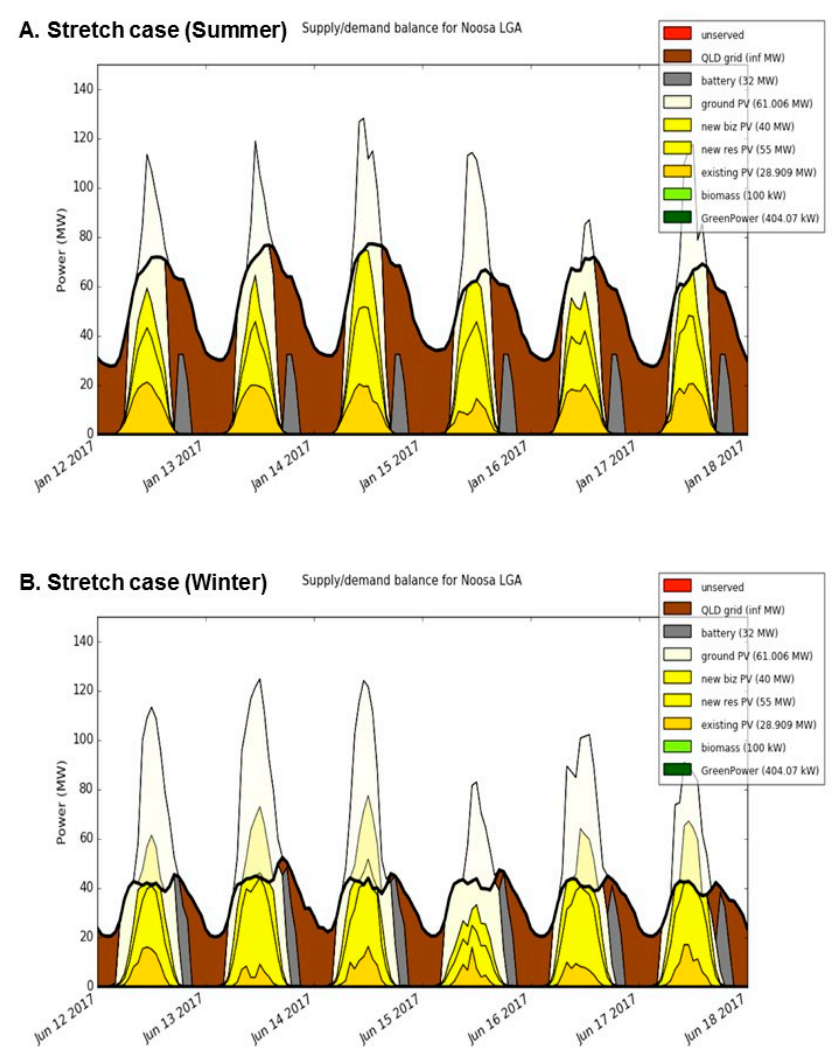

Figure 4. RE technology mix for Noosa-Stretch case ((A) summer, (B) winter) [26]. 


\subsection{The Final Toolbox of Options}

The specific recommendations from the final report, described as a toolbox of options, are described in Table 6. The toolbox of options can be used as required and could be adapted to suit other regions.

Table 6. Toolbox of Options.

\begin{tabular}{|c|}
\hline Recommendations \\
\hline i. Energy Info Hubs \\
\hline $\begin{array}{l}\text { A website could host information using a 'funnel' approach to direct enquirers to information most relevant to } \\
\text { their circumstances, as well as video testimonials relevant to installing solar PV. This could also link to online } \\
\text { tools such as the APVI Solar Potential Tool [29] and the Alternative Technology Association's Simulator. Local } \\
\text { Council may also wish to establish a shop front drop-in centre, from which Energy Assessors could operate }\end{array}$ \\
\hline ii. Solar Bulk Buy \\
\hline $\begin{array}{l}\text { A solar bulk buy could be implemented to make cheaper but good quality systems widely available to the } \\
\text { community. It should have both a standard and higher-end options, use local installers, provide a community } \\
\text { benefit, and could include batteries and SWHs }\end{array}$ \\
\hline iii. Solar \$avers \\
\hline $\begin{array}{l}\text { Local Council could pursue its own Solar } \$ \text { avers program where the upfront cost of a system is covered either } \\
\text { by the Council or by third party finance, which is then paid back through savings in electricity bills }\end{array}$ \\
\hline iv. Solar for Rentals \\
\hline $\begin{array}{l}\text { Information regarding the various options to overcome the 'split incentive barrier' should be included in a } \\
\text { 'Landlord Toolkit' }\end{array}$ \\
\hline v. Solar Access Rights \\
\hline $\begin{array}{l}\text { Local Council could develop a firm policy on how to address the issue of overshadowing of what could be a } \\
\text { significant financial investment in solar PV or SWHs }\end{array}$ \\
\hline
\end{tabular}

\section{vi. Multi-Site Feasibility Study}

Coordinate a multi-site feasibility study to help businesses obtain solar. The first stage would involve a high-level assessment of the viability of solar at each business. The second stage would involve a call for tenders for installers and an assessment of those tenders, then quality assurance of the completed installations

\section{vii. Solar PPAs and Leases}

Survey businesses and local Council to assess their interest in these options. If there is sufficient interest, this list could simply be made available to solar installers, or a multi-site feasibility study approach could be taken

\section{viii. Environmental Upgrade Agreements (EUAs)}

EUAs are where third-party finance is provided to a commercial site to undertake energy efficiency or renewable energy upgrades, where the finance is paid back by the local council, who then recoups this money through rates. Local Council could either undertake an investigation into whether EUAs may require legislative changes, or lobby the state government to do this themselves

\section{ix. Embedded Networks}

A survey/audit could be used to identify areas that have embedded networks, as well as their potential interest in installing solar. The outcomes of the survey/audit could be used to attract businesses who specialize in establishing and operating solar embedded networks

\section{x. Solar for Schools}

Assist government schools with the Queensland government's Advancing Clean Energy Schools program to acquire solar systems. This support should be extended to any government schools who are not included in the Advancing Clean Energy Schools (ACES) program, as well as any non-government schools and the wider educational sector

\section{xi. Community Organizations}

Local Council should undertake energy audits in conjunction with the Queensland government's EcoBiz program (Qld government initiative that helps businesses reduce energy, water, and waste costs) and then implement the recommendations

$$
\text { xii. Large-Scale Solar }
$$

Explore the different approaches to community ownership of large-scale renewable energy projects

$$
\text { xiii. Community-Owned Renewable Energy }
$$

Facilitate the development of community-owned renewable energy projects where appropriate 


\subsection{The Noosa Action Plan}

Noosa Shire Council is already actioning recommendations from the ITP report that are within their own jurisdiction. These include the creation of an Energy Information Hub and the Noosa Community Facilities Eco Initiative (NCFEI), which focuses on driving uptake of solar PV systems on community buildings. The Council's Energy Info hub will chiefly consist of a website that will offer Noosa residents easy access to information on how to decrease their carbon emissions. The NCFEI aims to have the council facilities occupied by community groups generate as much electricity from solar $\mathrm{PV}$ as they consume. A post-graduate university student currently on placement at Noosa Council has conducted sustainability audits in collaboration with EcoBiz on ten such council buildings.

Prior to using an external consultant, Zero Emissions Noosa had started developing a number of campaigns. As a result of the ITP report and the process used to develop it, these earlier campaigns have now been expanded into an action plan that consists of a number of community-led activities: (i) Repower Noosa Education, (ii) Renewable Energy Industry Cluster, (iii) Repower Noosa Business, (iv) Major Consumers, (v) Cooran Earth Rights partnership, (vi) Academic Zero Emissions Noosa, (vii). Repower Noosa Tourism, and (viii) Renters/Low-Income Households. This wide range reflects the need for different types of approaches for different types of people [3]. These initiatives are replicable and may be adapted to suit other communities with similar goals. The following describes these campaigns in further detail:

\section{i. Repower Noosa Education}

There are thirty-nine education facilities in Noosa Shire. These include: Primary schools, secondary schools, one university campus, one university hub, English language schools, and pre-school and day-care centers. Although educational facilities have load profiles that are a good match for solar, relatively small amounts of solar PV are installed on these facilities in the Noosa Shire. Repower Noosa Education aims to help education facilities understand how to become more energy-efficient and to increase their use of renewable electricity, so they become energy neutral. As per recommendations from ITP report, this group will assist public schools within the Noosa Shire to adopt the Advancing Clean Energy Schools program. This group will also help education facilities make the most of learning opportunities for their students if renewable energy is adopted and will also advise education facilities of financial incentive programs for renewable energy.

ii. Renewable Energy Industry Cluster

This group consists of local businesses owners who install rooftop PV systems within the Noosa Shire. The group, led by one of Zero Emissions Noosa's volunteers, convenes on a regular basis and aims to create a cohesive group of trusted PV installers. The modeling developed by ITP made it clear that this group will benefit financially if the 2026 Zero Emissions Noosa goal is pursued. Over $\$ 100$ million of investment will be required to meet Zero Emissions Noosa's target, which will create a significant number of local jobs. ITP estimated that twenty job years of work will be created for each MW installed in Noosa, and this will result in $\$ 80$ million of savings just in the avoided cost of paying for electricity to be generated elsewhere [26]. Currently, only four percent of local businesses have PV on their roofs. Zero Emissions Noosa has recently been awarded a Noosa Council Economic Grant to hire local consultants to study the barriers to getting local businesses to install solar. This project will also highlight the economic benefits for local businesses of installing solar and develop better marketing strategies for local solar installers. In line with recommendations from the ITP report, this group is considering doing a multi-site feasibility study to help businesses install PV systems.

iii. Repower Noosa Business

Working alongside the Renewable Energy Industry Cluster group, a group has been formed to encourage business owners to install solar. This group is still in its infancy and is currently deciding how to incorporate the recommendations from ITP into an action plan. So far, their plan is to approach small business owners in the local area and determine if they have an interest in installing PV systems.

iv. Major Consumers 
Another group just in its infancy is Major Consumers. This group will focus on the top ten or so electricity consumers in Noosa Shire, excluding Noosa Shire Council. In general, decision-makers for these 'larger' businesses do not live in the Noosa Shire so this group will need to operate outside the shire and will most likely focus on recommending embedded networks.

v. Cooran Earth Rights Partnership

Cooran is a small rural town in the north-western part of the Noosa Shire with a population of around 1600 people [30]. The residents of Cooran became aware of coal and gas exploration and mining licences that were going to be approved in the local area. Opposed to these mining operations, the residents of Cooran made a collective decision to make Cooran a coal-free town [31]. Consequently, on 11 August 2018, an official declaration was made that Cooran will be coal mine and gas field free. Cooran is in the process of developing strategies to ensure their electricity comes only from renewable sources. This group is currently considering which recommendations from the ITP report they will adopt.

\section{vi. Academic Zero Emissions Noosa}

Academic Zero Emissions Noosa is based at the CQUniversity campus in Noosa Shire, but includes researchers from universities across Australia. It is working in partnership with Zero Emissions Noosa by conducting academic research on activities undertaken to reach the $100 \%$ renewable electricity goal. To date, these activities include this research paper and an e-bike trial that is examining the health and wellbeing effects of using e-bikes as an alternate low emissions mode of travel in the Noosa Shire.

vii. Repower Noosa Tourism

Tourism Noosa is the leading tourism organization within the Noosa Shire. Tourism Noosa is "committed to the development of sustainable tourism" [32] and is a keen supporter of Zero Emissions Noosa. To date, although EcoBiz sustainability audits have been undertaken in several holiday rentals, the intention is to expand these to all such rentals in Noosa Shire-although this is proving to be difficult because landlords (some of who may live out of the shire) do not necessarily share Zero Emissions Noosa's goals. In addition to their current approaches based on the provision of information, Tourism Noosa has also expressed an interest in trialing the multi-site feasibility approach recommended by ITP.

viii. Renters/Low Income Households

It is recognized that inequity exists in regard to the uptake of solar for people from lower socio-economic backgrounds. Compared to the Australian average, people in Noosa have lower household incomes and higher rental costs [33]. The Renters/Low-income household group have decided to tackle the social issues that exist in Noosa by exploring the ITP Solar for Rentals recommendation.

\section{Discussion}

There are seventy-seven local government areas (Shires) in Queensland [34]. Zero Emissions Noosa is striving to achieve around $170 \mathrm{MWp}$ of renewable electricity capacity for the Noosa Shire by 2026 (Table 2). If the same target as Noosa's is adopted by the seventy-seven local government areas in Queensland, this would mean up to 13,000 MWp of renewable energy could be produced in Queensland. With $5500 \mathrm{MWp}$ of renewables needed in Queensland by 2020 [9], this highlights the significant contribution brought by this plan to the more general discussion about the transition to renewables in Australia.

For small areas such as Noosa, it is clear that local uptake of both energy efficiency and renewable generation options will not be enough to meet high renewable energy targets, and so large-scale renewables will be required. These can then be placed in locations outside regions such as Noosa, which can, therefore, be optimized for both renewable energy resources and transmission infrastructure.

However, a large amount of renewable generation for regions such as Noosa Shire will still come from distributed solar PV, which may result in some technical issues such as reverse power flow and voltage rise, especially under the Stretch scenario. Although there is a variety of options, both currently available and being developed, to address such technical impacts [35], including the distributed battery 
systems discussed here, they will add complexity and costs that must be paid for, ultimately by the community. However, the primary focus of this paper is on the significant challenge of developing appropriate strategies to enable the community to drive this uptake [36].

Such community-led projects are reported to complement more top-down approaches used by larger state-based schemes [37] and may, in fact, be more effective where larger schemes encounter political opposition [38]. They are also expected to result in outcomes that are more acceptable to the local community than those that are externally driven, and to help drive greater awareness of the social and environmental impacts of energy use, as well as to motivate people to take collective action as the results are more visible [5]. Another motivation for such groups is to act as an example to others, not only at the local government level, but to help drive more fundamental structural change called the 'regime' level [39] - by giving individuals and organizations a more practical understanding of what is involved. Similarly, McCauley and Stephens [36] report on the ability of such initiatives to accelerate broader change by promoting institutional thickness, generating a regional 'buzz' around sustainable energy activities, and by building trust between multiple and diverse stakeholders.

Community groups with goals of decreasing emissions are seeking "high quality, clear, in-depth information and working examples" [40] (p. 20) to help them to make informed decisions. The process of using an external consultant, as described in this case study, had a number of benefits, including engaging the broader community in setting the modeling parameters and helping them to get a better understanding of what they were trying to achieve. It also provided the community with the context within which their actions would be undertaken, as well as valuable background information on the technologies and business models available to drive the uptake of renewable energy technologies. This helped to focus their efforts on options that were technically feasible, financially viable and within their capabilities to implement. Once the report was written, it could then be used to call meetings with relevant stakeholders and act as a catalyst to decide on specific courses of action. This process gave the community and local government a 'rallying point' and resulted in the toolbox of options they could use in their chosen action plan, which was credible in the eyes of the community. Up to that time, although there was a significant amount of enthusiasm to undertake some sort of action, there had been a general feeling of aimlessness with no real sense of purpose or direction.

Interestingly, the subsequent actions taken to date by the Noosa community very much reflect activities that were already in place in the community (outlined in Section 3), albeit generally in a germinal state. This highlights the benefits of providing a toolbox of options that can be used as desired, rather than prescribing a particular process that should be followed. Similarly, the modeling proved important by indicating that the focus should be on solar PV rather than some other technology [41]. The main purpose of using an external consultant was to provide a report that would provide a focus for the community, illustrate the high-level impacts, and to generate a credible plan that could be used to achieve the zero emissions target.

Even where the particular initiatives discussed in Section 3 do not use any of the toolbox of options, they have all benefited from the increased exposure of the overall project to the wider community. There is also some evidence that the community actions taken in Noosa may result in more widespread change by encouraging cooperation between multiple and diverse stakeholders $[39,40]$, for example, the Repower Noosa Education, Major Consumers and Repower Noosa Tourism campaigns. Although it is too early to determine how effective the Noosa Action Plan will be, it is clear that the process followed to date has provided focus and galvanized action in a way that is compatible with the community's interests and motivations.

\section{Conclusions}

Within Australia, strategies are underway on a federal, state, regional land community level to decrease greenhouse gas emissions. However, it is likely that achieving significant levels of renewable energy in Australia will require a considerable amount of uptake driven by the community. With the diverse nature of communities, and their reliance on volunteer effort, the process used to engage, 
inform, and motivate them is critical. This paper reports on a community group in the Noosa Shire in south-east Queensland called Zero Emissions Noosa that is working toward a common goal, to emit zero emissions in the Noosa Shire by 2026. This paper described what residents within the Noosa Shire have done and are currently doing to achieve this goal. One of the strategies adopted by Zero Emission Noosa was to commission an external consultant to develop a strategy to achieve the 2026 zero emissions goal. Inclusion of the broader community in all stages of the report building process, from the selection of modeling assumptions and scenarios, to the identification of feasible technologies, to the creation of realistic options to drive uptake, was critical. The modeling scenarios identified the need for significant levels of uptake of energy efficiency, local distributed PV as well as large-scale PV and/or wind power most likely outside Noosa - with a total of around $170 \mathrm{MWp}$ required. Recommendations from the final report provided Zero Emissions Noosa with clear direction and a pathway to achieve their zero emissions goal. Tools, modeling, and processes described within this study can be adapted to suit other community groups with similar zero emissions goals. Other community groups will benefit by adopting strategies used by Zero Emissions Noosa that are described within this paper.

Author Contributions: The authors made the following contributions to this paper: conceptualization, C.A., R.P., J.D.V.; methodology, R.P.; formal analysis, R.P.; investigation, R.P.; writing—original draft preparation, C.A., R.P.; J.D.V., R.S.; writing一review and editing, C.A., R.P., J.D.V., R.S.

Funding: This research received no external funding.

Acknowledgments: The authors would like to thank ITP Renewables for producing the report described in this paper. The authors would also like to acknowledge that Rob Passey was an author of the ITP report.

Conflicts of Interest: The authors declare no conflict of interest.

\section{Appendix A}

The following provides an overview of the ITP report in order to illustrate the particular issues that are most relevant to, and how they affect, the community's choices.

\section{Appendix A.1 The Australian Renewable Energy Target (RET)}

As discussed above, the Australian RET is expected to result in about 23.5\% of Australia's electricity coming from renewable sources by 2020 [6]. However, it is made up of two components which have different impacts on the strategies selected by Zero Emissions Noosa: (i) the Large-scale Renewable Energy Target (LRET) and (ii) the Small-scale Renewable Energy Scheme (SRES).

Renewable energy systems with a rated peak capacity of $100 \mathrm{kWp}$ upwards create a Large Generation Certificate (LGC) for every MWh of electricity they produce. If the solar PV systems built in Noosa Shire are greater than $100 \mathrm{kWp}$, they can be used to meet the LRET. For wind power the size limit is $10 \mathrm{kWp}$, and for hydro is $6.4 \mathrm{kWp}$ [42]. The use of renewable energy systems that generate LGCs would mean that other renewable energy systems, that otherwise would have been built to meet the target, no longer need to be built. Thus, any such systems built in Noosa would not increase the total amount of renewable energy generated in Australia (unless the LGCs are instead extinguished and not used to meet the target, as occurs for GreenPower and the ACT government's reverse auctions). This information is important because there was a clear desire in the community consultation sessions for Noosa's renewable electricity to be additional. Note that, after 2020, enough renewable energy generation should have been built to meet the 33,000 GWh target, which in theory means there will be no more demand for LGCs, and so their value should approach zero. In this case, any new large-scale plant would be built without using LGCs, in which case they would be additional to the LRET target.

The SRES applies to renewable energy systems that are no greater than $100 \mathrm{kWp}(10 \mathrm{kWp}$ for wind and $6.4 \mathrm{kWp}$ for hydro), and also uses certificates that each correspond to $1 \mathrm{MWh}$ of renewable electricity, that are called Small-scale Technology Certificates (STCs). The SRES is different to the LRET in that the STCs are not used to meet a target. Instead, no matter how many are created, they must all be bought by electricity retailers in Australia. This means that, if renewable energy systems built in 
Noosa Shire are built using STCs, they will be additional to any legislated target and so will increase the total amount of renewable energy generated in Australia. This was particularly relevant to the Noosa community because this smaller size range was more within their direct control. The Queensland $50 \%$ target is different to both the LRET and the SRES in that it is not a legislated target and does not involve the use of certificates. As such, it is not affected by the above additionally issues-however all generation used to meet the RET contributes to the Queensland 50\% target.

\section{Appendix A.2 Impact of Renewable Energy Targets on Achieving 100\% Goals}

Through the community consultation process, it became clear that there was a general belief that the electricity generated because of the Australian Renewable Energy Target would reduce the amount of renewable electricity that Noosa needed to generate in order to meet its $100 \%$ target. Thus, the section on high-level issues provided valuable information to the community by explaining that even when the RET is reached, and $23.5 \%$ of the electricity used Australia-wide is from renewable sources, this does not mean that only another $76.5 \%$ of renewable electricity needs to be produced to reach the $100 \%$ target. Rather, until $100 \%$ is reached, a percentage of the remainder will always be from fossil fuel generation, and so to reach the $100 \%$ RE target, all Noosa's electricity must be from renewable sources.

\section{Appendix A.3 What Renewable Energy Generation Can Count towards Noosa's 100\% RE Target?}

This was a particularly complex issue to discuss with the community. For example, does generation from a PV system only count towards Noosa's 100\% RE target if the PV is located in Noosa, or if it is paid for by someone from Noosa, or if the electricity is used by someone in Noosa, or all three? An alternative point of view relates to whether the renewable electricity is additional, or in other words, whether it only came about because of the actions of the Noosa residents.

This question generally only applies to systems greater than $100 \mathrm{kWp}$. A residential or business behind-the-meter PV system that is less than $100 \mathrm{kWp}$ will be additional because if that household or business did not have it installed, then no one else would have, and as discussed above, it will be additional to the RET. In addition, the system is owned by someone in Noosa and the electricity will be used within Noosa. PV systems greater than $100 \mathrm{kWp}$ are more complex. As discussed above, if they use LGCs, they will not be additional to the legislated target. If such a system does not use LGCs and is built within Noosa and is owned by people in Noosa, it could be said to be additional and to contribute to Noosa's 100\% RE target. All this information was useful to the Noosa community, although consensus has not been reached on how to ensure that a system greater than $100 \mathrm{kWp}$, that is built outside Noosa (as it is likely for a large ground mount PV system or wind farm) is additional and so can contribute to the $100 \%$ target. This will need to be addressed by the Noosa community when such large-scale generation is built and will presumably be based on the relative importance of: (i) who it is owned by, (ii) who pays for the generated electricity, and (iii) the degree to which the residents of Noosa are responsible for its construction.

\section{References}

1. United Nations Framework Convention on Climate Change. Report on the Structured Expert Dialogue on the 2013-2015 Review. Available online: http://unfccc.int/resource/docs/2015/sb/eng/inf01.pdf (accessed on 17 December 2018).

2. Oztig, L. Europe's climate change policies: The Paris Agreement and beyond. Energy Sources Part B Econ. Plan. Policy 2017, 12, 917-924. [CrossRef]

3. Bergek, A.; Mignon, I. Motives to adopt renewable electricity technologies: Evidence from Sweden. Energy Policy 2017, 106, 547-559. [CrossRef]

4. Saheb, Y.; Shnapp, S.; Johnson, C. The Zero Energy concept: Making the whole greater than the sum of the parts to meet the Paris Climate Agreement's objectives. Curr. Opin. Environ. Sustain. 2018, 30, 138-150. [CrossRef] 
5. Rogers, J.C.; Simmons, E.A.; Convery, I.; Weatherall, A. Social impacts of community renewable energy projects: Findings from a woodfuel case study. Energy Policy 2012, 42, 239-247. [CrossRef]

6. Department of the Environment and Energy. The Renewable Energy Target (Ret) Scheme. Available online: http://www.environment.gov.au (accessed on 12 January 2019).

7. Victoria State Government. Victoria's Renewable Energy Targets. Available online: https://www.energy.vic. gov.au (accessed on 20 December 2018).

8. ACT Government. Our Canberra: 100\% Renewable Energy for Canberra by 2020. Available online: https://www.act.gov.au (accessed on 11 December 2018).

9. Queensland Renewable Energy Panel. Credible Pathways to a 50\% Renewable Energy Target for Queensland: Final Report. Available online: https://www.dnrm.qld.gov.au (accessed on 18 November 2018).

10. CIA-Central Intelligence Agency. The World Factbook: Australia. Available online: https://www.cia.gov/ library/publications/the-world-factbook/geos/as.html (accessed on 18 November 2018).

11. City of Melbourne. Zero Net Emissions by 2020-Update 2014. Available online: https://www.melbourne. vic.gov.au/SiteCollectionDocuments/zero-net-emissions-update-2014.pdf (accessed on 16 January 2019).

12. City of Sydney. Sustainable Sydney 2030-Community Strategic Plan. Available online: http://www.cityofsydney.nsw.gov.au/_data/assets/pdf_file/0005/99977/6645_Final-version-CommunityStrategic-Plan-IPR-Document_FA4-1_low-res.pdf (accessed on 15 January 2019).

13. CitySmart. How Brisbane City Council Went Carbon Neutral. Available online: https://www.citysmart.com. au/blog/brisbane-city-council-went-carbon-neutral (accessed on 15 January 2019).

14. City of Perth. Environment Strategy. Available online: https://www.perth.wa.gov.au/sites/default/files/ documents/City\%20of\%20Perth\%20Environment\%20Strategy.pdf (accessed on 20 November 2018).

15. City of Adelaide. Carbon Neutral Adelaide-Action Plan 2016-2021. Available online: https://www.cityofadelaide.com.au/assets/94335_BSA_Carbon_Neutral_Adelaide_Action_Plan_2016_ 2021_FIN_WEB_v6.pdf (accessed on 21 November 2018).

16. Frankston City Council. Carbon Neutral Action Plan 2012-2016. Available online: http://www.frankston.vic.gov.au/files/assets/public/environment_and_waste/environment/pdfs/carbon_ neutral_action_plan_-_frankston_city_council_2012_-_2016.pdf (accessed on 20 November 2018).

17. Moreland City Council. Zero Carbon Evolution: Getting on Track to a Carbon Neutral Moreland Community. Available online: http://www.moreland.vic.gov.au/globalassets/key-docs/policy-strategy-plan/zero-carbonevolution-strategy.pdf (accessed on 15 January 2019).

18. Zero Emissions Byron. Our history. Available online: https://zerobyron.org/about/our-history (accessed on 19 January 2019).

19. Noosa Parks Association. Committee and Project Officers. Available online: http://www.noosaparks.org.au (accessed on 8 December 2018).

20. Gloster, M. The Shaping of Noosa; Noosa Blue Publishing Group: Noosaville, Australia, 1997.

21. Noosa Council. Mayor and Councillors. Available online: https://www.noosa.qld.gov.au/mayor-councillors (accessed on 13 February 2019).

22. Zero Emissions Noosa Working Groups. Available online: http://zeroemissionsnoosa.com/working-groups/ index.html (accessed on 1 February 2019).

23. Noosa Council. Zero Emissions organisational strategy 2016-2026. Available online: https://www.noosa.qld. gov.au/documents/40217326/40227860/Zero\%20Emissions\%20Organisational\%20Strategy.pdf (accessed on 10 February 2019).

24. Noosa Council. Waste and Recycling. Available online: https://www.noosa.qld.gov.au/waste-recycling (accessed on 10 February 2019).

25. Noosa Biosphere. Roadmap to $100 \%$ Renewable Energy. Available online: https://noosabiosphere.org.au (accessed on 28 June 2019).

26. ITP. Achieving 100\% Renewable Electricity in Noosa. Available online: https://www.zeroemissionsnoosa. com.au/strategic-plan (accessed on 28 June 2019).

27. Gallent, N.; Ciaffi, D. Community Action and Planning: Contexts, Drivers and Outcomes; Policy Press: Bristol, UK, 2014.

28. Australian PV Institute (APVI). Mapping Australian Photovoltaic installations. Available online: http: //pv-map.apvi.org.au/historical\#10/-26.3156/152.9681 (accessed on 12 November 2018). 
29. Australian Bureau of Statistics (ABS). 1270.0.55.006 - Australian Statistical Geography Standard (ASGS): Correspondences. July 2011. Available online: https://www.abs.gov.au/AUSSTATS/abs@.nsf/DetailsPage (accessed on 2 November 2018).

30. Australian Bureau of Statistics. 2016 Census QuickStats Cooran. Available online: http://quickstats. censusdata.abs.gov.au (accessed on 2 December 2018).

31. Zero Emissions Noosa. Celebrating Cooran's Community Power. Available online: https://www. zeroemissionsnoosa.com.au/repower-cooran-1 (accessed on 28 June 2019).

32. Tourism Noosa. About Tourism Noosa. Available online: http://www.visitnoosa.com.au (accessed on 15 January 2019).

33. Zero Emissions Noosa. Achieving 100\% Renewable Electricity in Noosa. PowerPoint Presentation. Available online: http://zeroemissionsnoosa.com (accessed on 19 November 2018).

34. Queensland Government. Local Government Directory. Available online: https://www.dlgrma.qld.gov.au/ local-government-directory.html (accessed on 28 June 2019).

35. AEMO. Technical Integration of Distributed Energy Resources: Improving DER capabilities to benefit consumers and the power system. In A Report and Consultation Paper; Australian Energy Market Operator, Australian Government: Melbourne, Australia, 2019.

36. McCauley, S.M.; Stephens, J.C. Green energy clusters and socio-technical transitions: Analysis of a sustainable energy cluster for regional economic development in Central Massachusetts, USA. Sustain. Sci. 2012, 7, 213-225. [CrossRef]

37. Akizu, O.; Bueno, G.; Barcena, I.; Kurt, E.; Topaloğlu, N.; Lopez-Guede, J.M. Contributions of Bottom-Up Energy Transitions in Germany: A Case Study Analysis. Energies 2018, 11, 849. [CrossRef]

38. Passey, R.; Bailey, I.; Twomey, P.; MacGill, I. The inevitability of 'flotilla policies' as complements or alternatives to flagship emissions trading schemes. Energy Policy 2012, 48, 551-561. [CrossRef]

39. Berry, S.; Davidson, K.; Saman, W. The impact of niche green developments in transforming the building sector: The case study of Lochiel Park. Energy Policy 2013, 62, 646-655. [CrossRef]

40. Braun, P.; McEachern, S. Climate Change and Regional Communities: Towards Sustainable Community Behaviour in Ballarat. Australas. J. Reg. Stud. 2010, 16, 3-22.

41. Houlihan Wiberg, A.; Georges, L.; Dokka, T.H.; Haase, M.; Time, B.; Lien, A.G.; Mellegård, S.; Maltha, M. A net zero emission concept analysis of a single-family house. Energy Build. 2014, 74, 101-110. [CrossRef]

42. Australian Government Clean Energy Regulator. How to participate in the Renewable Energy Target. Available online: http://www.cleanenergyregulator.gov.au/RET/How-to-participate-in-the-RenewableEnergy-Target (accessed on 19 November 2018). 